\title{
TROPICÁLIA: MANOBRAS ESTRATÉGICAS EM REDES DE MÚSICOS
}

\section{RESUMO}

Este artigo busca construir pontes entre três campos teóricos: Teoria Organizacional, Redes Sociais e Identidade Social. Por meio da análise de redes de músicos brasileiros, monitoramos a emergência de novos estilos, paralelamente às mudanças estruturais na rede. Durante o período de análise, de 1958 a 1969, quatro estilos musicais se consolidaram: Bossa N ova, Jovem Guarda, M PB e Tropicália. Utilizamos a análise de redes sociais para obter três dimensões da evolução do campo: evolução da rede, criação de buracos estruturais e transformação da centralidade dos atores. Conflitos internos em um campo criam oportunidades de intermediação entre grupos separados por buracos estruturais. Essas lacunas podem ser gradativamente conectadas a partir de transformações incrementais nas redes dos artistas. Com a maior influência de artistas emergentes, aumenta a possibilidade de introdução de um novo estilo e modificação do sistema classificatório do campo.

\section{Charles Kirschbaum}

Centro Universitário da FEI

\section{Flávio Carvalho de Vasconcelos}

FGV-EAESP

\begin{abstract}
This article aims to build bridges between three theoretical fields: Organizational Strategy, Social N etworks, and Social Identities. By analyzing the networks of Brazilian musicians (interpreters and composers), we monitor the emergence of new styles, along with the structural changes in the network. Within the period in analysis, from 1958 to 1969, four musical styles emerge and consolidate: Bossa N ova, Jovem Guarda, M PB and Tropicália. We utilized Social Networks Analysis in order to grasp three dimensions of the field evolution: network evolution, creation of structural holes and transformation of actors' centrality. Internal conflicts in a field generate brokerage opportunities among groups separated by structural holes. These holes might be gradually bridged through incremental transformations in the artists' networks. As the emerging artists' influence increases, there is higher potential for the introduction of a new style and change of the field's classificatory system.
\end{abstract}

PALAVRAS-CHAVE Gestão estratégica, teoria organizacional, redes sociais, música popular brasileira, indústria cultural. KEMORDSStrategic management, organizational theory, social networks, Brazilian popular music, cultural industry. 


\section{INTRODUÇÃO}

O clássico estudo de Weick (1969) sobre a formação de sentido em organizações foi um dos primei ros a considerar o problema de que grande parte da atividade administrativa refere-seà classificação de objetos, o que permite sejam tratados de forma apropriada dentro de sistemas teóricos. Todavia se reconhece que a realidade é mais complexa do que as categorias como tentamos captá-la. Matériasprimas aceitáveis precisam ser separadas de materiais de baixa qualidade, mas efetivamente surgem surpresas no chão de fábrica. Os pacientes hospitalares precisam ser constantemente en quadrados em al guma doença conhecida e tratados de acordo (Weick, Sutcliffee Obstfeld, 2005), mas ainda assim os médicos cometem erros.

Os sistemas de categorias existem entre os humanos desde o início da civilização (Durkheim, 1915), dando sustentação à operação das instituições (Douglas, 1986). 0 setor musical depende de sistemas categóricos (e simbólicos). Assim, a caracterização ocorre quando do lançamento de novos ál buns (Dimaggio, 1987). As gravadoras, do mesmo modo que as lojas de discos e as estações de rádio, aplicam rótulos aos registros musicais e a seus criadores. Esses rótulos são estilos. Para os músicos, o processo de rotulagem é ambivalente. Por um lado, a música é considerada legítima, nos termos das categorias existentes. Por outro, el es lutam para manter sua peculiaridade e liberdade de mudar. Em outras palavras, os músicos procuram manter sua identidade intacta e livre de tipificação.

Este artigo investiga as tensões entre os músicos e a indústria de discos, explorando a emergência da Tropicália, um movimento musical brasileiro. Para tanto, constrói pontes entre três conceitos importantes da teoria das organizações. Reúne uma teoria das redes sociais, uma teoria da identidade euma teoria do comportamento estratégico. A contribuição que se propõe a fazer é integrar essas três perspectivas numa só explicação teórica do comportamento estratégico que seja dependente tanto da identidade individual dos atores sociais quanto da configuração da rede em que se inserem. A emergência da Tropicália é um fenômeno privilegiado para essa análise, pois engendrou a construção das identidades sociais mediante a mobilização de recursos simbólicos.

Após esta breve introdução, nosso estudo começa revendo a literatura sobre o comportamento estratégico em redes. Esta perspectiva é complementada com a proposta de que a identidade individual e a posição na rede sejam conceitos que se reforçam mutuamente, dando à luz a idéia de identidade inserida. Em seguida, introduzimos nosso objeto de estudo: redes de artistas ( intérpretes e composi- tores) da indústria fonográfica brasilei ra durante a década de 1960. 0 período em análise, que vai de 1958 a 1969, revela a emersão de diversos novos estilos musicais no Brasil, inclusive a Bossa N ova, a M PB, a Jovem Guarda e a Tropicália. N uma primeira análise, exploramos qual itativamente a história desses estilos concorrentes. A revisão da história da indústria da música fornecerá o pano de fundo necessário para entender a análise quantitativa de rede que faremos a seguir. Ao enunciar as entidades analisadas nessa rede (intérpretes, compositores, LPs, canções e estilos), podemos então descrever a metodologia usada e os resultados observados. Encerramos o artigo com uma discussão e sugestões para pesquisas futuras.

\section{REFERENCIAL TEÓRICO}

\section{Abordagem da sociologia econômica}

Powell e Smith-Doerr (1994, p. 368) sugerem que os pesquisadores têm tratado as redes sociais de duas maneiras: como "dispositivo analítico" e como "dispositivo de governança". De acordo com o primeiro ponto de vista, que representa o foco deste estudo, as estruturas em rede podem restringir o comportamento dos atores: "Redes de relações entre indivíduos em diferentes organizações e entre organizações em um campo são críticas para explicar como as organizações adotam estruturas semel hantes e seguem estratégias comuns". 0 conceito intuitivo é 0 de que a posição de um ator numa rede pode representar um caminho privilegiado ou um obstáculo ao acesso a recursos e informações rel evantes. Em outras palavras, a posição na rede influencia as estratégias que os atores podem adotar. Para esclarecer esse conceito, apresentamos a seguir uma abordagem às redes sociais.

White (2002a) sugere que todo mercado tem sua identidade. Tal identidade é certamente estabel ecida por meio de monitoramento cruzado e narrativas compartilhadas. Ainda assim, ela não está fortemente atrelada às redes sociais propriamente ditas. Podolny (1993), por outro lado, sugere que atores mal posicionados podem procurar interromper a identidade do mercado para promover um reposicionamento da identidade. $\mathrm{Na}$ seção a seguir, exploramos como os pesquisadores em redes sociais desenvolvem a idéia de posicionamento.

\section{Rumo aos buracos estruturais}

A intuição de que a ação estratégica está fortemente relacionada à rede social em que se opera tem suas raízes nos sociólogos clássicos. Um conceito central é o capital 
social inspirado em fechamento (closure) ${ }^{1}$ desenvolvido separadamente por Coleman (1990) e Bourdieu (1986).

Adotando o conceito weberiano de fechamento (closure), tanto Coleman quanto Bourdieu interpretam o capital social como sendo os el os que podem ser mobilizados para explorar recursos. Ademais, para proteger os membros de um grupo e restringir a distribuição de recursos, essas formas sociais convergem no sentido de formar redes fechadas e "panelas". Ao mesmo tempo, os indivíduos são coagidos a consentir com a identidade do grupo para manter sua qualidade de membros. Essa identidade grupal pode ser aplicada num nível institucional ou no individual. Krackhardt (1990) demonstra que, mesmo em situações em que as instituições permitem que os indivíduos estabel eçam elos com pessoas externas, podem advir sanções informais por parte de outros membros.

Granovetter (1973) retoma essa discussão ao analisar as "tríades proibidas". Segundo Granovetter, se A estiver fortemente ligado a B e B estiver fortemente ligado a C , então A e C estarão necessariamenteligados, seja por um elo forte ou por um elo fraco. Isso se deve à escassez de recursos disponíveis para a manutenção dos relacionamentos. Se o recurso "tempo" for fortemente investido por A em seu relacionamento com $B$, haverá pouco tempo disponível para $B$ investir em $C$, a menos que haja forte sobreposição entre o tempo que $A$ passa com $B$ e $o$ tempo que $B$ passa com $C$. Assim, deve haver um relacionamento entre A e $C$ (Figura 1a). U m el emento central desse argumento é 0 fato de que, embora elos fortes sejam regidos por normas grupais, elos fracos são menos limitados. Dessa forma, representam o papel de pontes entre grupos.

Por outro lado, Burt (1992) sugere que poderia haver "tríades proibidas". Ele concebe uma tríade com apenas duas arestas (Figura 1 b), abrindo a possibilidade de estratégias de corretagem para o ator que ocupa a posição central da tríade. Com isso, o autor se opôs aos defensores do fechamento enquanto capital social. Em sua análise das redes sociais, Burt concebeu a idéia de "buracos estruturais". Partindo da concepção de Simmel quanto a situações em que um indivíduo se beneficia do conflito entre dois outros, Burt (1992) sugere a idéia de buracos estruturais. A idéia original de Simmel, baseada na expressão latina "tertius gaudens" ("Iucros de terceiros"), explica a liberdade de ação que um indivíduo obtém da intermediação de uma tríade que, do contrário, estaria fechada (Simmel, 1950).

A definição de buracos estruturais, para Burt, "é o relacionamento de não-redundância entre dois contatos" (Burt, 1992, p. 18). Partindo dessa perspectiva, se os nodos circunvizinhos ao ator $X$ estiverem fortemente interligados entre si, haverá poucas oportunidades de arbitragem para $X$. Isso se deve à el evada redundância entre os elos de X - um fluxo muito baixo de novas informações entre esses elos. Inversamente, se os nodos circunvizinhos de $X$ estiverem pouco interligados entre si, haverá para $X$ diversas oportunidades de corretagem de informações entre esses elos, o que conferirá el evada importância à sua posição na rede.

A referida corretagem (e a própria manutenção da tríade aberta) somente será possível se o intermediário explorar ou fomentar a discórdia ou uma separação significativa entre os intermediados. É certo que, sendo a discórdia ou a separação al go necessário para que a tríade se mantenha aberta, então devemos observar, com o passar do tempo, a formação de fortes identidades opostas entre os membros intermediados. Se por um lado essa segregação proporciona ao empreendedor uma oportunidade de intermediação, traz também um desafio: como é possível estabelecer relacionamentos com ambas as partes litigantes sem com isso colocar em jogo sua própria legitimidade?

Figura 1 - Tríades fechada e aberta.

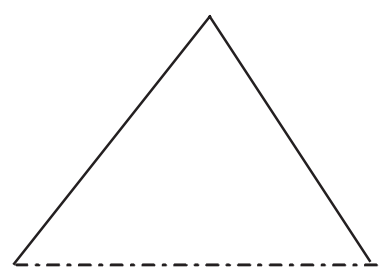

(a) Tríade de Granovetter: forte ou fraca

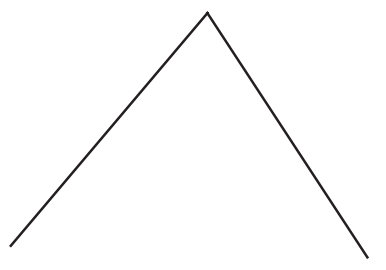

(b) Tríade aberta de Burt 


\section{Redes sociais e identidades sociais}

A identidade social tem sido tradicionalmente tratada na teoria sociológica como um atributo dos indivíduos. Hogg, Terry e W hite (1995), por exemplo, traçam um perfil da pesquisa sobre identidade em que representam a teoria da identidade e a teoria da identidade social como duas perspectivas assemelhadas de mediação dinâmica do self socialmente construído entre o comportamento individual e as estruturas sociais. Argumentam os autores que, embora praticamente inexista comunicação sistemática entre as duas perspectivas, elas compartilham de muitos traços em comum.

Aqueles autores mostram que a teoria da identidade é uma teoria microssociológica que busca explicar comportamentos relacionados a papéis. A teoria da identidade social, por outro lado, tem suas raízes em estudos de psicologia social e procura explicar o comportamento grupal e intergrupal. Essas teorias da identidade, embora levem em consideração as várias facetas do ambiente do indivíduo, definem a identidade em termos de valores compartilhados e da pertinência a determinadas categorias previamente definidas (como raça, nacionalidade, profissão, etc.).

Neste artigo, propomos a idéia da identidade como adoção de papel, introduzindo diversos insights relacionados a redes. Como propõem Berger e Luckmann (1966) e Scott (2001), o primeiro passo na construção da identidade social se dá quando os atores exteriorizam estruturas simbólicas por meio de suas ações e interações. Com isso, a representação da identidade de uma pessoa é dependente do reconhecimento por parte dos pares dos atores.

White (1992), por sua vez, propõe que os atores estabelecem identidades sociais para controlar seus padrões de relacionamento com outros atores. Por exemplo, em sociedades primitivas, as identidades baseadas em gênero estavam intimamente ligadas a relacionamentos específicos, na medida em que apenas os homens caçavam juntos, etc. Na medida em que esses atores são capazes de estabelecer relacionamentos que não são previstos por seus papéis, ocorre então a transformação social. White (2002b) chamou de "cat-net" (dos termos ingleses categories - categorias - e network - rede) a incongruência entre a identidade e os relacionamentos de uma pessoa, uma vez que 0 ator engaja-se, simultaneamente, numa identidade categórica que não corresponde a suas interações sociais.

Segundo esse ponto de vista, a identidade inserida é constantemente transformada, à medida que 0 ator estabelece novos relacionamentos ao longo de sua trajetó- ria. Essa idéia tem sido defendida por DiMaggio (1993) quando este autor explora o que chama de paradoxo de $N$ adel. Esse paradoxo apresenta as inconsistências entre os papéis sociais consolidados (pai, mãe, professor, etc.) e os el os real mente existentes entre os indivíduos. Sempre que um indivíduo estabelece com sucesso relacionamentos que fogem ao roteiro descrito pelo papel social, há uma oportunidade de inovação do papel social em si. É a isso que White (1993) se refere como "ação fresca" numa rede social.

$\mathrm{N}$ a medida em que a adoção identitária é o passe de entrada para a rede empírica, os atores adotarão identidades (Zuckerman, 2003). Contudo, a adoção de identidades tem seu preço - uma vez adotado, um rótulo pode prender os atores (o fenômeno do typecasting), reduzindo sua mobilidade no espaço social. Alternativamente, relacionamentos discretos estabelecidos fora do grupo de identidade podem proporcionar aos atores certo grau de liberdade. Como sugerem Padgett e Ansell (1993), os atores podem seguir uma estratégia de "ação robusta" e estabelecer elos com grupos opostos. Isso se dá por meio de uma cautelosa compartimentalização dos atores litigantes, como sugere Burt. Por outro lado, os atores poderiam atacar a ordem simbólica como um todo (Podolny, 1993). O Quadro 1 resume os conceitos vistos até este ponto.

Nas anál ises a seguir, descreveremos como os músicos brasileiros se engajaram em identidades sociais, desengajaram-se dessas mesmas identidades por meio da "ação robusta" e acabaram por recriá-las.

\section{MÚSICOS EM REDES SOCIAIS: EMERGÊNCIA DA TROPICÁLIA}

O objeto escolhido para esta investigação é uma rede de músicos. Consideramos apropriado este objeto tendo em vista as seguintes razões: primeira, o consumo de bens culturais está fortemente relacionado com a criação identitária (Simmel, 1957); segunda, os próprios artistas precisam se engajar em um grupo identitário, pelo menos no começo da carreira, para serem aceitos pela indústria (Rao, M onin, e Durand, 2003); e terceira, os artistas procurarão diferenciar sua identidade percebida para criar uma imagem exclusiva perante a indústria e o público (Peterson, 1997).

Mais especificamente, escolhemos os períodos de 1958 a 1969 da Música Popular Brasileira pelo acelerado surgimento de novos estilos: Bossa Nova (BN ), Jovem Guarda (JG ), M PB e Tropicália. Cada um desses estilos não apenas 
se baseava em diferentes regras musicais, como também correspondia a diferentes identidades sociais. 0 fenômeno que desejamos observar é a interação desses estilos do ponto de vista da criação identitária baseada em redes por parte desses artistas.

\section{Bossa Nova (BN): o paradigma da classe média em ascensão}

A emergência da BN é vista por muitos historiadores da música brasileira como um fenômeno da classe média carioca. Tinhorão (1997), por exemplo, destaca o deslocamento da classe média emergente para a Zona Sul do Rio de Janeiro como um dos pré-requisitos da BN. À medida que essa nova classe média começou a tomar forma, houve a necessidade de se estabelecer uma nova identidade. No meio musical, essa classe não podia identificar-se com a música romântica adotada pela classe al ta tradicional nem com o tradicional samba das classes mais baixas. A solução pareceu ser incorporar 0 jazz à música brasileira.

A influência do jazz sobre a música brasileira é observada desde a década de 1940 ( Medaglia, 2003). Quando Antônio Carlos Jobim e outros pioneiros da BN começaram a experimentar as primeiras combinações do samba com o jazz, a música criada era ainda um estilo híbrido. Foi a incorporação ao grupo de João Gilberto (CASTRO, 2003), e de sua maneira ímpar de tocar o violão, que permitiu à BN adquirir uma identidade musical muito distinta. Ao mesmo tempo, a BN tornou-se o estilo musical mais influente daquela geração de músicos.

\section{A Jovem Guarda (JG) pop e seu contraponto à BN}

Paral elamente à emergência da BN, diversos artistas começaram a introduzir o rock and roll na música brasileira. Liderado principalmente por Roberto Carlos e Erasmo Carlos, o estilo da Jovem Guarda (JG) procurava criar ou recriar o rock em português. Este ficou também conhecido como "iê-iê-iê" por suas adaptações das primeiras canções dos Beatles, ou simplesmente como música pop. É importante observar que o estilo JG estava predominantemente ligado o rock dos anos 1950 e 1960. A revolução pela qual passou o rock com o surgimento dos Rolling Stones ou com a segunda fase dos Beatles não foi absorvida pela JG.

Se a BN alinhou a classe média emergente com o espírito intelectualizado do jazz, a JG trouxe a jovialidade do rock. Assim, a oposição do Jazz e do Rock traduziu-se para a música brasileira.

\section{Surgimento da MPB e seu confronto com a JG}

Desde a emergência da BN houve debate quanto a ser ela um estilo nacional legítimo ou uma mera adaptação do jazz. Carlos Lyra, um dos pioneiros da BN, dá início, a uma determinada al tura, à criação de uma nova versão da BN de aspecto mais brasileiro. Nara Leão, juntamente com Lyra, começou a lançar canções de forte conteúdo crítico social, procurando estabelecer uma síntese entre a BN e a música de protesto. Foi o início da MPB.

Expoentes da M PB, como Elis Regina e Chico Buarque, ocuparam um espaço musical que fora deixado para trás

Quadro 1 - Síntese de conceitos da sociologia econômica e insights em redes sociais.

\begin{tabular}{|l|l|}
\hline \multicolumn{1}{|c|}{ CONCEITO } & \multicolumn{1}{c|}{ INSIGIIS EM REDES SOCIAIS } \\
\hline Identidade do mercado & $\begin{array}{l}\text { - Os mercados têm identidades decorrentes do pareamento de compradores e } \\
\text { fornecedores. }\end{array}$ \\
\hline Identidade individual enquanto posicionamento & $\begin{array}{l}\text { - Padrões constantes de relacionamento geram "posições". } \\
\text { - Os indivíduos se posicionam nas redes sociais, assumindo identidades. }\end{array}$ \\
\hline Fenômeno da rotulagem e typecast & $\begin{array}{l}\text { - As identidades sociais, na qualidade de categorias de rotulagem, podem pren- } \\
\text { der seus detentores. } \\
\text { - O custo do deslocamento identitário pode superar os ganhos percebidos. }\end{array}$ \\
\hline "Cat-net" & $\begin{array}{l}\text { - Os atores podem ser capazes de buscar elos fora dos roteiros de seus papéis. } \\
\text { - O descasamento entre a identidade e os relacionamentos de uma pessoa pode } \\
\text { desencadear a emersão de novas identidades. }\end{array}$ \\
\hline Ação robusta & $\begin{array}{l}\text { - Os atores são capazes de criar uma ponte sobre um buraco estrutural entre gru- } \\
\text { pos opostos por meio da compartimentalização de interações. }\end{array}$ \\
\hline Alteração da ordem simbólica & $\begin{array}{l}\text { Os atores podem procurar atacar a ordem simbólica visando um reposiciona- } \\
\text { mento geral. }\end{array}$ \\
\hline
\end{tabular}


pelos músicos tradicionais da BN, que desenvolviam carreira fora do Brasil. A criação de uma identidade de conteúdo e forma nacionalista proporcionou uma revitalização da BN e levou à reintrodução de sambistas tradicionais como Noel Rosa.

As características "nacionalista" e "de protesto" da identidade da M PB levaram muitos de seus compositores e intérpretes a recusar qualquer expressão musical que revelasse influência estrangeira. Embora a BN tradicional fosse fortemente influenciada pelo jazz, foi o estilo JG 0 alvo dos ataques da MPB. Para os músicos da M PB, o uso que a JG fazia das guitarras elétricas e sua tentativa de assimilar o rock equivalia a uma alienação da juventude brasileira em relação à realidade do país.

O conflito atingiu o clímax quando 0 Fino da Bossa, um programa televisivo encabeçado por Elis Regina, começou a perder audiência para o Jovem Guarda, encabeçado por Roberto Carlos. Elis Regina, em resposta aos avanços da JG, promoveu uma parada intitulada "Parada contra as Guitarras Elétricas". Esse movimento estabeleceu fortes fronteiras em torno da M PB e da $J G$, esclarecendo as identidades que cercavam os dois estilos. Por causa da ascendência comum dos grupos da BN e da MPB e da alta mobilidade de artistas entre eles, é possível afirmar que integravam uma só comunidade BN/M PB.

\section{Os "Baianos" penetram a comunidade BN/ MPB}

0 grupo da MPB, apesar de forte, não foi capaz de articular todos os artistas da comunidade BN/M PB para que se posicionassem contra o estilo JG. Músicos tradicionais da BN , como Tom Jobim e João Gilberto, deram continuidade a suas carreiras no estrangeiro.

Por outro lado, recém-chegados como os "Baianos" (vindos do estado da Bahia), seriam mais resistentes ao descarte de novas possibilidades musicais, como o uso de guitarras elétricas. Ao empregarem guitarras elétricas, músicos como Caetano Vel oso, Gilberto Gil e os M utantes posicionaram-se entre os estilos BN/M PB eJG. Essa posição se viu sob forte ataque dos artistas da M PB.

\section{A Tropicália se estabelece e ganha influência}

0 uso de guitarras elétricas, trajes alternativos e letras sardônicas deixaram os "Baianos" e os Mutantes numa posição incômoda. Senão eram atacados pela comunidade da M PB, eram vistos simplesmente como um experimento exótico que não teria grande sobrevida.

Fazia-se necessário criar uma nova identidade musical para conferir legitimidade à musica de Caetano, de Gil e dos Mutantes (Calado, 1997). Quando nasceu a identidade "Tropicália", seu discurso diferia do apresentado pela BN/M PB: defendia que a música brasileira não deveria se fechar ao mundo. Com efeito, a música da Tropicália incorporava el ementos da BN , da M PB e da JG. Ademais, afirmava que a arte não deveria se subordinar à política (Veloso, 1997). N esse sentido, o movimento Tropicália lembrava o de escritores do século XIX, que visava à criação de um campo artístico autônomo, independente tanto da aristocracia quanto do mercado (Bourdieu, 2002).

Seu sucesso levou muitos novos artistas à adoção de um estilo mais eclético. É provável que o elemento mais impressionante da influência da Tropicália tenha sido a interpretação, por Elis Regina, de uma canção de Roberto Carlos em 1969, proclamando a queda da mural ha entre MPB e JG. A seguir, o leitor pode apreciar um sumário dos estilos musicais brasileiros mencionados.

\section{COMPREENSÃO DOS ESTILOS E IDENTIDADES DE UMA PERSPECTIVA DE REDE/ INSERÇÃOO}

U ma pergunta crucial a que este artigo deve responder é a de como pode a análise de redes melhorar ou fornecer qual quer insight adicional que já não tenha sido qualitativamente descrito. A resposta está na própria definição de identidade.

\section{IDENTIDADES ENTRE MÚSICOS}

Ao analisar o estilo de um músico, o objeto direto de investigação é a canção interpretada. Canções surgem do trabalho dos primeiros compositores, que as adicionam a um repositório de conhecimento. Em seguida, os intérpretes ganham acesso a esse repositório e tomam de empréstimo canções para gravar. Ao interpretar uma canção, um intérprete aplica a ela seu próprio estilo. Esse estilo, então, é a fusão da canção utilizada, dos instrumentos usados e da própria maneira de interpretar. Uma vez gravado o título, os críticos musicais (assim como o pessoal da indústria, os músicos e o próprio público) aplicarão a ele um rótulo de estilo de acordo com seu próprio conjunto de critérios (Dimaggio, 1987). Assim, o estilo é uma forma social representada que se atribui a objetos artísticos. Dessa forma, um objeto de arte pode ser reclassificado à medida que os critérios subjacentes mudam, com o passar do tempo (Danto, 1964; Polos, Hannan e Carroll, 2002).

Por exemplo, "Coração materno" (M otherly Heart), 
escrita por Vicente Celestino, foi considerada "brega" pela comunidade BN/M PB em meados da década de 1960. $M$ as quando Caetano Veloso a interpretou e gravou para o LP Tropicália, foi considerada pel os críticos como al go novo, se não satírico, e ao mesmo tempo uma retomada das raízes brasileiras.

Dessa forma, podemos acompanhar a evolução de um artista simplesmente por meio da compreensão da origem das canções que ele toma emprestado. Lena (2004) usa uma metodologia semel hante para mapear as identidades de DJs de rap. Como os DJs "citam" outros rappers em suas samplings de canções, Lena pôde construir uma rede social de rappers pelos DJs. Aplicamos a mesma intuição ao mapear a rede social compositor pelo intérprete. 0 padrão do repertório (o conjunto de canções interpretadas) pode variar de uma maneira que a identidade formal não prevê. Outro exemplo: tome-se a evolução de $N$ ara Leão: foi ela uma das intérpretes pioneiras da BN. N ão obstante, foi também uma das primeiras a começar a recuperar antigos sambistas. Foi preciso algum tempo para que a MPB se estabelecesse como síntese entre a BN e o estilo samba que a antecedeu, de maneira a reclassificar $\mathrm{N}$ ara Leão sob a MPB. Argumentamos ser possível revelar a identidade emergente de um artista a partir de mudanças em seu repertório.

\section{Criação de redes pelos repertórios}

Podemos imaginar três redes entre músicos: uma rede de compositores, uma de intérpretes e outra de compositores e intérpretes. Essas três redes são importantes para a compreensão da estrutura do campo dos músicos. N este artigo, contudo, nos concentraremos principalmente na rede entre compositores e intérpretes, uma vez que ela revela uma dimensão da criação identitária dos intérpretes.
À medida que os intérpretes alteram seu repertório, sinalizam uma mudança de identidade. No mesmo sentido, se as canções de um compositor são mais tocadas, é possível dizer que ele se tornou mais influente na definição das identidades dos intérpretes. 0 conceito de influência abrange diversos significados. A maneira de J oão Gilberto tocar o violão podeser considerada um tipo de influência. Contudo, neste artigo, a influência é definida e medida pelo empréstimo que um compositor faz de suas composições a interpretes.

Do ponto de vista das redes, as "redes de ego" dos intérpretes mudam à medida que a identidade deles muda (uma rede de ego é a rede imediata em torno do ator anal isado). Paral elamente, a centralidade do compositor pode aumentar ou diminuir à medida que sua influência cresce ou decai.

\section{METODOLOGIA}

\section{Base de dados}

N ossa análise abrange o período entre 1958 e 1969. M ais especificamente, começa com o lançamento do LP C anção do amor demais (Vinicius de M oraes, 1958) e se encerra com o LP Elis Regina in London (Elis Regina, 1969). A escolha desses dois registros não é arbitrária. 0 primeiro estabeleceu a BN como novo estilo, enquanto o segundo traz Elis Regina interpretando Roberto Carlos, o que contribuiu para a confusão das fronteiras que delimitavam M PB, JG e Tropicália.

Incluímos ainda em nossa base de dados 89 LPs gravados por intérpretes selecionados durante o período (Tabela 1). Os álbuns incluídos foram os constantes do website http://cliquemusic.uol.com.br/artistas, que exclui compactos. Os intérpretes escol hidos foram os seguintes:

Quadro 2 - Perfis da Bossa Nova, Jovem Guarda, MPB e Tropicália.

\begin{tabular}{|l|l|l|l|}
\hline \multicolumn{1}{|c|}{ ESTILOS } & \multicolumn{1}{|c|}{ CARACTERÍSTICAS MUSICAIS } & \multicolumn{1}{c|}{ TEMAS } & PRINCIPAIS COMPOSITORES \\
\hline Bossa Nova (BN) & $\begin{array}{l}\text { - Influência do jazz } \\
\text { - Ritmo de violão de J.Gilberto }\end{array}$ & - Amor, natureza & $\begin{array}{l}\text { - João Gilberto } \\
\text { - Vinicius de Moraes } \\
\text { - Tom Jobim }\end{array}$ \\
\hline MPB & $\begin{array}{l}\text { - Retorno ao samba e às raízes } \\
\text { brasileiras }\end{array}$ & $\begin{array}{l}\text { - Crítica social } \\
\text { - Guitarra elétrica } \\
\text { - Influência do rock }\end{array}$ & $\begin{array}{l}\text { - Chico Buarque } \\
\text { - Edu Lobo }\end{array}$ \\
\hline Jovem Guarda (JG) & - Influências ecléticas & - Ecléticos da juventude & $\begin{array}{l}\text { - Roberto Carlos } \\
\text { - Erasmo Carlos }\end{array}$ \\
\hline Tropicália & & $\begin{array}{l}\text { - Caetano Veloso } \\
\text { - Gilberto Gil }\end{array}$ \\
\hline
\end{tabular}


João Gilberto, Tom Jobim, Vinicius de Moraes, Carlos Lyra e Nara Leão, da BN; Elis Regina, Chico Buarque e Edu Lobo, da MPB; Roberto Carlos, Erasmo Carlos e Wanderlea, da JG; e Caetano Veloso, Gilberto Gil, Maria Bethânia, Gal Costa e os Mutantes, do grupo dos "Baianos" e da Tropicália. ${ }^{2}$

Embora lidemos com uma amostra limitada de intérpretes, acreditamos que cada um represente bem seu próprio estilo. Para cada LP, incluímos todas as canções e seus compositores. Isso representou uma base de dados total de 950 canções e 552 músicos, inclusive os intérpretes mencionados, co-intérpretes e compositores. Partindo dos LPs, pudemos construir três bases de dados relacionais essenciais: 'LPs e intérpretes'; 'LPs e canções'; e 'canções e compositores'.

Orientados por essas bases de dados relacionais, construímos então uma quarta, relacionando 'intérpretes e compositores', dada por: intérprete $X$ está presente no LP "A", que contém a canção " $B$ ". A canção "B" é composição dos compositores " $Y$ ". Assim, transitivamente, " $X$ " tomou de empréstimo uma canção de " $Y$ ", estabelecendo um el o. A 'base de dados relacional' entre compositores e intérpre- tes assim constituída éa base para as redes que desejamos construir para analisar a identidade dos intérpretes.

\section{Sociogramas}

Partindo da base de dados de 'compositores e intérpretes', construímos quatro sociogramas que representam, graficamente, os relacionamentos entre compositores e intérpretes. Os quatro sociogramas correspondem a quatro subperíodos: (i) de 58 a 61, (ii) de 62 a 65, (iii) de 66 a 67 , e (iv) de 68 a 69.

O motivo para estarem os oito primeiros anos agrupados em períodos de 4 anos éa baixa densidade de relacionamentos nesse intervalo. 0 campo da BN estava apenas começando em 1958, de modo que vários dos intérpretes selecionados ou ainda não gravavam ou não produziam em níveis rel evantes. A partir do momento em que o campo desenvolveu elevada densidade (1966), agrupamos os anos remanescentes em períodos de dois anos (a Tabela 2 traz um sumário do número de atores, elos e densidade de cada período).

Em termos de filtragem, o processo baseou-se em contar, em cada um desses períodos, o número de canções

Tabela 1 - Número de LPs consultados por intérprete.

\begin{tabular}{|c|c|c|c|c|}
\hline \multirow{2}{*}{ PRINCIPAL INTÉRPRETE } & \multicolumn{4}{|c|}{ PERÍODO } \\
\hline & $58-61$ & $62-65$ & $66-67$ & $68-69$ \\
\hline Chico Buarque & & & 2 & 2 \\
\hline Carlos Lyra & 2 & 3 & & 2 \\
\hline Caetano Veloso & & & & 4 \\
\hline Erasmo Carlos & & 1 & 3 & 1 \\
\hline Edu Lobo & & 1 & 1 & 1 \\
\hline Elis Regina & 1 & 6 & 3 & 3 \\
\hline Gal Costa & & & 1 & 2 \\
\hline Gilberto Gil & & & 1 & 2 \\
\hline João Gilberto & 1 & 1 & 1 & \\
\hline Maria Bethânia & & 1 & 1 & 2 \\
\hline Mutantes & & & & 2 \\
\hline Nara Leão & & 4 & 4 & 2 \\
\hline Roberto Carlos & 1 & 4 & 2 & 2 \\
\hline Tom Jobim & 3 & & 1 & 1 \\
\hline Vinicius de Moraes & 2 & 1 & 4 & 1 \\
\hline Wanderlea & & 3 & 2 & 1 \\
\hline Total & 10 & 25 & 26 & 28 \\
\hline
\end{tabular}


emprestadas por cada compositor a cada intérprete. Isso produziu uma matriz $\mathrm{M}$ por $\mathrm{N}$, onde " $\mathrm{m}$ " é o número de compositores e " $n$ " é o número de intérpretes. Devido ao grande número de compositores, tivemos de adotar critérios para captar apenas os relacionamentos relevantes para nossa análise. Assim, mantivemos de cada matriz apenas os relacionamentos de valor igual ou superior a 2, o que significa que, para que um relacionamento compositor/ intérprete constasse do gráfico, o compositor deveria ter emprestado pelo menos duas canções ao intérprete no período em tela.

Além disso, transformamos todos os relacionamentos em relacionamentos dicotômicos. Por exemplo, se 0 compositor $Y$ emprestou 10 canções ao intérprete $X$ e 0 compositor $Z$ emprestou 3 canções ao intérprete $X$, os dois relacionamentos, Y-X e Z-X obtêm valor 1 ; do contrário, sendo emprestadas menos de 2 canções, o rel acionamento tem valor nulo. Embora as técnicas de rede permitam a análise da força do relacionamento, investigamos apenas a existência de relacionamentos entre artistas. Isso também afeta a interpretação dos sociogramas: a duração dos elos não tem como significado senão a existência de um relacionamento.

\section{Análise de rede}

Partindo da base de dados relacional de compositores e intérpretes, construímos uma rede simétrica (matriz quadrada) de compositores, de maneira semelhante ao esforço de mapeamento da rede de músicos brasileiros por Lima e Silva e seus associados (Lima e Silva, Medeiros, et al., 2004). A força do relacionamento entre compositores foi estabelecida pelo número de canções em que apareciam juntos. ${ }^{3}$ Partindo dessa rede, extraímos 0 grau de centralidade de F reeman ${ }^{4}$ para monitorar os movimentos dos compositores nas redes (Tabela 3). Quanto mais central for um compositor, maior número de elos terá com intérpretes (Wasserman e Faust, 1994). Assim, quanto maior a centralidade de um compositor, maior sua influência.
Além disso, com a ajuda do U cinet (Borgatti, Everett e Freeman, 2002), dividimos, para cada período, os compositores e intérpretes em duas facções para testar a identidade inter e intragrupal. A metodologia de criação de facções segue um algoritmo que maximiza a probabilidade de que uma partição de nodos seja semelhante a uma "panela" (ver Amorim, Barthélemy e Ribeiro, 1992, para detalhes sobre a metodologia de facções).

A metodologia de facções foi utilizada para explorar a existência de grupos informais latentes por meio do agrupamento de nodos com elevada densidade de elos entre si. Por exemplo, Lazzarini e Joaquim (2004) usaram a metodologia de facções para identificar alianças em potencial entre companhias aéreas. Enquanto Lazzarini e J oaquim identificaram cinco facções, decidimos localizar apenas duas. A divisão em apenas duas facções atende bem a nosso propósito de testar a polarização do campo musical em dois subcampos.

Uma vez identificadas quatro facções para cada período (duas de intérpretes de duas de compositores), esperamos queidentidades fortes levem a elevada en dogenia. Sea identidade de um intérprete frentea sua facção for fortee altamente diferenciada em relação à facção oposta, é de se esperar que as canções por ele gravadas pertençam apenas à facção respectiva de compositores. Por exemplo, é de se esperar que a facção Bossa N ova reproduza as canções de João Gilberto e seus colegas. No mesmo sentido, não seria de se esperar que reproduzissem canções de Roberto Carlos. A aderência dos intérpretes à identidade de sua facção é medida pela porcentagem de canções interpretadas que pertençam à facção de seus compositores (Tabela 4). Se a porcentagem for elevada, isso significa que a maioria das canções da facção é tomada de empréstimo à facção esperada de compositores.

\section{RESULTADOS}

A apresentação dos resultados desta pesquisa é feita em três etapas. Primeiro, descrevemos toda a evolução

Tabela 2 - Evolução da rede - principais estatísticas.

\begin{tabular}{|l|c|c|c|c|}
\hline & \multicolumn{5}{|c|}{ PERÍODO } \\
\cline { 2 - 5 } & $58-61$ & $62-65$ & $66-67$ & $68-69$ \\
\hline Número de compositores & 69 & 225 & 200 & 178 \\
\hline Número de elos & 750 & 1.227 & 927 & 1.119 \\
\hline Densidade (elos/ compositores) & 10,87 & 5,45 & 4,64 & 6,29 \\
\hline
\end{tabular}


da rede: número de compositores, número de elos e densidade (elos por compositor) (Tabela 2). Em seguida, introduzimos o sociograma de compositores e intérp retes para ilustrar visual mente os atuais arranjos dos atores. Finalmente, comentamos a centralidade dos compositores na rede de compositores. Essa análise final permite o embasamento de insights qualitativos do sociograma em dados concretos do grau de centralidade.

\section{Emersão da BN e da JG: 1958-1961}

O surgimento da BN na indústria fonográfica contou com baixa densidade de compositores (69), devido ao baixo número de LPs gravados. Ainda assim, a densidade de el os é el evada: 10,9, indicando importante sobreposição de compositores e LPs lançados.

A análise do sociograma (Figura 2) mostra a formação de duas redes distintas: BN, à esquerda, eJG, do lado direito. Não estão visualmente presentes el os que unam essas redes. M as quando anal isamos a aderência à identidade, na Tabela 4, observamos que a dos intérpretes BN aos compositores BN é elevada (99\%), enquanto a dos JG à sua própria facção de compositores é menor (55\%). Essa conclusão sugere que a identidade BN foi forte desde 0 início e que a da JG ainda estava em processo de estruturação.

Quando passamos à análise do grau de centralidade de Freeman, Carlos Lyra surge como o compositor com maior número de elos, seguido de Tom Jobim, Dorival Caymmi e Bôscoli, todos da BN . João Gilberto é apenas o quinto da classificação, apesar de sua decisiva contribuição para o estabel ecimento do ritmo da BN. Não obstante, a menor centralidade de João Gilberto confirma a afirmação dos intérpretes de que Gilberto fora principalmente um modelo de interpretação, não uma fonte de canções (Homem de M ello, 1976). Tal distinção entre compositores e intérpretes torna-se menos clara durante os Festivais de Música da década de 1960.

Tabela 3 - Grau de centralidade de Freeman de compositores selecionados.

\begin{tabular}{|c|c|c|c|c|}
\hline \multirow{2}{*}{ COMPOSITORES } & \multicolumn{4}{|c|}{ PERÍODO } \\
\hline & $58-61$ & $62-65$ & $66-67$ & $68-69$ \\
\hline Caetano Veloso & $\mathrm{N} / \mathrm{A}$ & $176(0,2 \%)$ & $65(0,4 \%)$ & $1(3,2 \%)$ \\
\hline Tom Jobim & $2(4,6 \%)$ & $34(0,6 \%)$ & $5(1,5 \%)$ & $2(2,8 \%)$ \\
\hline Vinicius de Moraes & $7(2,7 \%)$ & $2(2,1 \%)$ & $1(3,3 \%)$ & $3(2,8 \%)$ \\
\hline Capinan & $\mathrm{N} / \mathrm{A}$ & N/A & $14(1 \%)$ & $4(2,7 \%)$ \\
\hline Gilberto Gil & $\mathrm{N} / \mathrm{A}$ & $\mathrm{N} / \mathrm{A}$ & $2(2 \%)$ & $5(2,3 \%)$ \\
\hline Edu Lobo & $\mathrm{N} / \mathrm{A}$ & $4(1,8 \%)$ & $9(1,2 \%)$ & $6(2,2 \%)$ \\
\hline Erasmo Carlos & $\mathrm{N} / \mathrm{A}$ & $6(1,7 \%)$ & $3(1,8 \%)$ & $7(1,8 \%)$ \\
\hline Roberto Carlos & $\mathrm{N} / \mathrm{A}$ & $7(1,7 \%)$ & $13(1 \%)$ & $8(1,8 \%)$ \\
\hline Torquato Neto & N/A & N/A & $8(1,2 \%)$ & $9(1,8 \%)$ \\
\hline Ronaldo Bôscoli & $4(3,6 \%)$ & $212(0,1 \%)$ & $57(0,5 \%)$ & $10(1,5 \%)$ \\
\hline Baden Powell & $\mathrm{N} / \mathrm{A}$ & $12(1,1 \%)$ & $10(1,1 \%)$ & $11(1,4 \%)$ \\
\hline Chico Buarque & $\mathrm{N} / \mathrm{A}$ & N/A & $4(1,6 \%)$ & $13(1,4 \%)$ \\
\hline Roberto Menescal & $58(0,8 \%)$ & $\mathrm{N} / \mathrm{A}$ & $\mathrm{N} / \mathrm{A}$ & $14(1,4 \%)$ \\
\hline Carlos Lyra & $1(4,9 \%)$ & $1(2,4 \%)$ & $7(1,2 \%)$ & $16(1,1 \%)$ \\
\hline Dorival Caymmi & $3(3,6 \%)$ & $18(0,8 \%)$ & $32(0,5 \%)$ & $19(0,9 \%)$ \\
\hline Carlos Imperial & $8(2,3 \%)$ & $\mathrm{N} / \mathrm{A}$ & $6(1,3 \%)$ & $141(0,2 \%)$ \\
\hline João Gilberto & $5(2,7 \%)$ & N/A & $155(0,3 \%)$ & N/A \\
\hline Newton Mendonça & $6(2,7 \%)$ & $225(0,1 \%)$ & $159(0,3 \%)$ & $\mathrm{N} / \mathrm{A}$ \\
\hline Zé Keti & N/A & $9(1,3 \%)$ & $16(1 \%)$ & $\mathrm{N} / \mathrm{A}$ \\
\hline
\end{tabular}

Observação: Classificados por centralidade (participação na centralidade normalizada). 


\section{Consolidação da BN e da JG: 1962-1965}

De 1962 a 1965 (início dos Festivais de Música na TV), os movimentos BN e JG ganham força. 0 número de LPs registrados no período aumenta para 25 e o de compositores chega a 225. A densidade, contudo, cai para 5,5, sugerindo maior diversificação do repertório.

O sociograma deste período (Figura 3) mostra duas redes separadas, BN no topo e JG abaixo. Na verdade, ape- nas Castro Perret estabeleceu uma ligação entre os dois movimentos, porém não o suficiente para atenuar suas fronteiras. A aderência à identidade (Tabela 4) mostra um elevado grau de diferenciação entre os dois grupos. Cerca de $82 \%$ das canções gravadas por intérpretes BN são da facção BN. A mesma proporção se observa no grupo JG.

Ainda assim, surgem em cena al guns players novos e importantes: Elis Regina e Nara Leão. Ambas articularão

Tabela 4 - Aderência de intérpretes e compositores a facções.

\begin{tabular}{|c|c|c|c|c|}
\hline & \multicolumn{4}{|c|}{ PERIODO } \\
\hline & $58-61$ & $62-65$ & $66-67$ & $68-69$ \\
\hline \multicolumn{5}{|l|}{ Número de: } \\
\hline Intérpretes BN (MPB) & 3 & 13 & 27 & 15 \\
\hline Intérpretes JG (Tropicália) & 3 & 3 & 3 & 12 \\
\hline Compositores BN (MPB) & 35 & 95 & 72 & 77 \\
\hline Compositores JG (Tropicália) & 34 & 130 & 128 & 101 \\
\hline Aderência interp./ comp. BN (MPB) & $99 \%$ & $82 \%$ & $84 \%$ & $79 \%$ \\
\hline Aderência interp./ comp. JG (Trop.) & $55 \%$ & $82 \%$ & $82 \%$ & $86 \%$ \\
\hline
\end{tabular}

Figura 2 - Rede de intérpretes e compositores de 1958 a 1961.

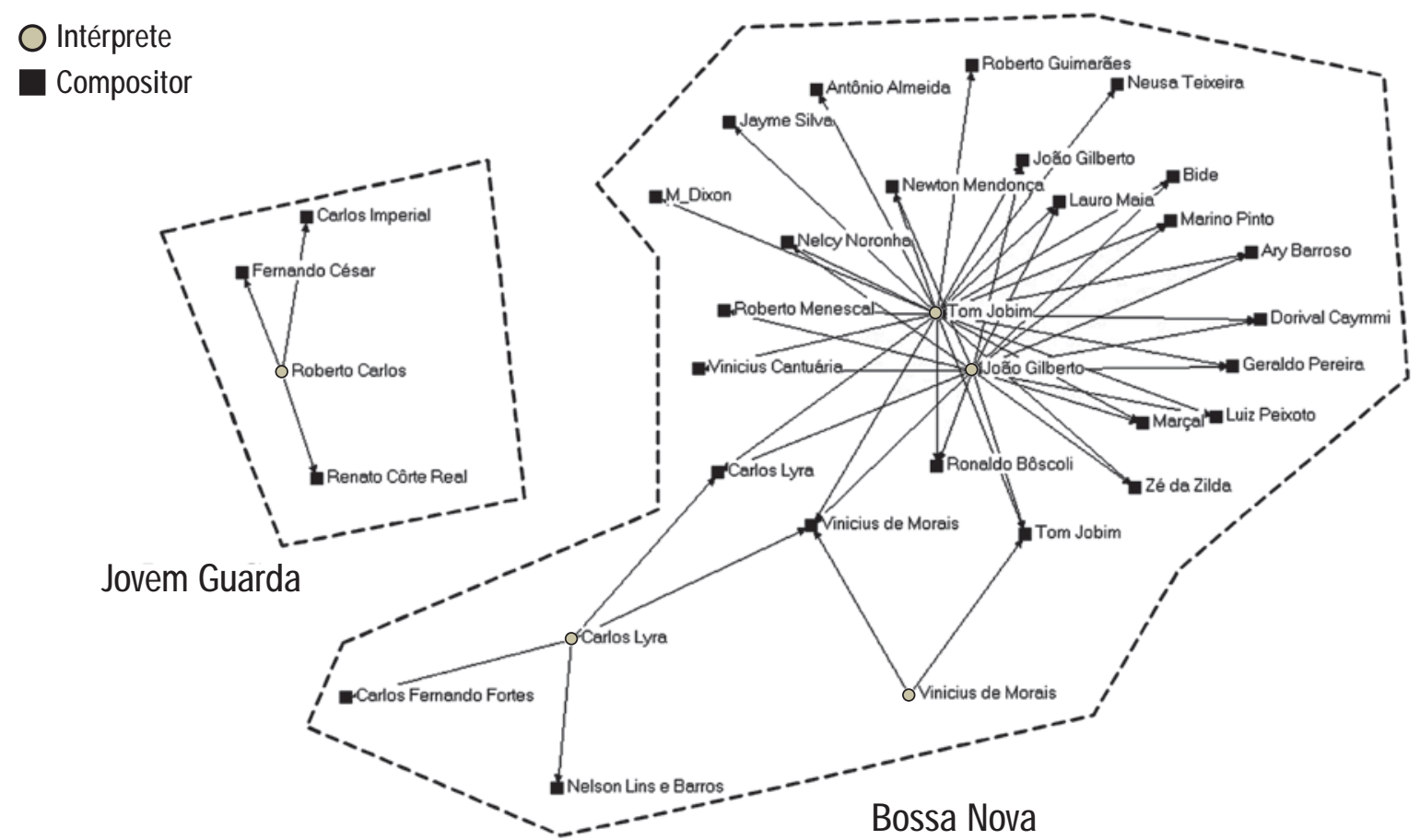


não apenas compositores BN tradicionais, mas também sambistas tradicionais, além de novos compositores, como Edu Lobo e Baden Powell, que revigoraram a BN eabriram caminho para a M PB. Interessante observar al guns nodos desligados das duas redes principais: Maria Bethânia, tomando de empréstimo canções de Caetano e N oel Rosa. Isso marca o surgimento dos "Baianos", ainda não muito bem integrados a qualquer das redes.

Carlos Lyra ainda é o mais central dos compositores da rede, seguido de Vinicius de M oraes. Mas emergem novos atores da BN : Edu Lobo, em quarto lugar, e Zé Kéti, em nono. Paralelamente, a JG se estrutura e aumenta a centralidade de seus compositores: Erasmo Carlos atinge a sexta posição, seguido de Roberto Carlos.

\section{Emergência da MPB: 1966-1967}

Embora o período abrangido tenha diminuído para dois anos, a efervescência do período se revela em seus valores. 0 número de LPs chega a 26 e 0 de compositores atinge 200. Não surpreende que a densidade de compositores caia para 4,6. Com a estruturação do campo, os intérpretes buscam uma maior diversidade de repertório na tentativa de se diferenciar.
O sociograma do período (Figura 4) revela o pico da era dos F estivais. A M PB emerge como derivação da rede da BN . Aliás, as duas redes estão al tamente interligadas, o que sugere uma comunidade relativamente integrada, embora não homogênea. 0 núcleo da BN é de alta densidade, enquanto os recém-integrados compositores da M PB aparecem esparsos e periféricos. Observamos a rede JG ainda separada (no topo da Figura 4). Os "Baianos" foram absorvidos pela comunidade BN/M PB, emprestando canções principalmente a intérpretes da MPB (como Elis Regina). A diferenciação entre os dois grupos também se observa a partir da aderência do repertório (Tabela 4). Oitenta e quatro por cento das canções executadas pela facção BN/M PB vêem de seus compositores prediletos. A JG apresenta aderência relativamente elevada, 82\%.

A ausência de pontes entre as redes sugere a existência de um buraco estrutural que pode ser eventual mente explorado. Caetano, Gil, Mutantes e outros músicos desejavam criar uma ponte entre BN/M PB e JG, explorando esse buraco estrutural. M as havia um obstáculo a ser superado: como introduzir um novo estilo se as fronteiras entre BN/MPB e JG eram tão rígidas?

Figura 3 - Rede de intérpretes e compositores de 1962 a 1965.

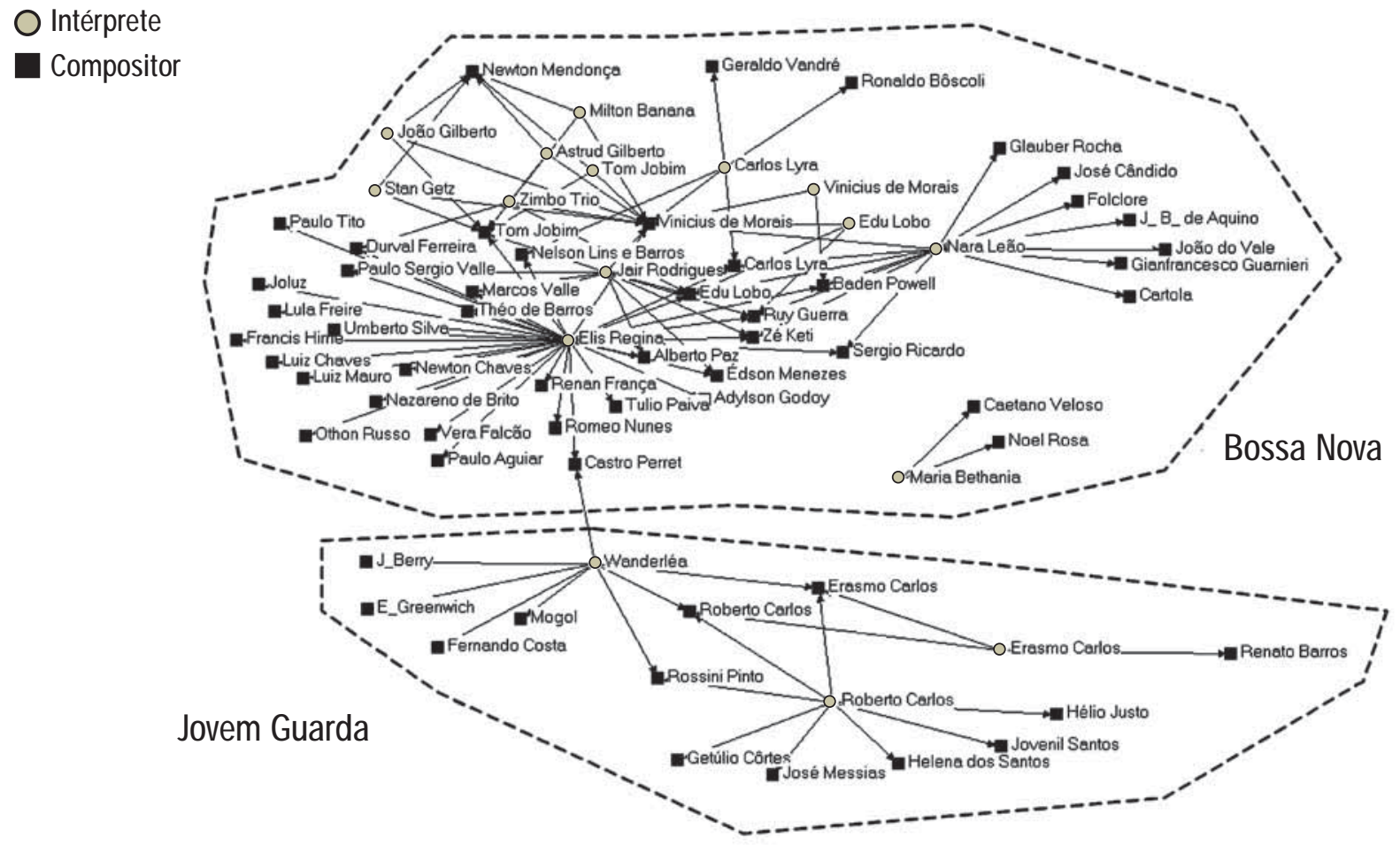


A centralidade dos atores revela algumas mudanças importantes com a emergência da M PB. Os compositores da BN ainda são centrais (Vinicius de M oraes ocupa a primeira posição), mas Gilberto Gil já alcança o segundo lugar e Chico Buarque se vê em quarto na classificação de centralidade. Os compositores da JG mantêm elevada centralidade devido ao crescente sucesso da facção: Erasmo Carlos está em terceiro lugar, com Carlos Imperial em sexto. Caetano Veloso, não tão bem conectado quanto Gilberto Gil, fica com a 65a posição. A pesar dessa fraca classificação se comparado a seu par, Gil, Caetano preservará maior liberdade de movimentos na próxima fase da evolução da Música Brasileira.

\section{Emergência da Tropicália: 1968-1969}

No período em tela, o número de LPs aumenta um pouco, para 28, enquanto 0 de compositores cai para 178. A densidade também cai, para 6,3, sugerindo menor diversidade à medida que 0 campo se consolida. A análise do sociograma (Figura 5) dá, finalmente, resposta à nossa hipótese: a emergência do movimento
Tropicália explora o buraco estrutural entre os grupos BN/MPB e JG.

Os "Baianos" (Caetano Veloso, Gilberto Gil, Gal Costa) e outros aliados (como os Mutantes) se colocam entre os movimentos BN/M PB e JG, tanto como intérpretes, tomando de empréstimo tanto canções quanto compositores, como dando canções em empréstimo. Os intérpretes da JG emprestam canções à Tropicália e executam as canções desta última. 0 mesmo vale para o grupo BN/MPB.

A endogenia da facção BN/M PB chega final mente à sua menor taxa histórica, de 79\% (Tabela 4), indicando uma maior porosidade de seu repertório. Além disso, a facção JG aumenta sua aderência ( $86 \%$ ) e seu porte ( 12 intérpretes, contra o nível histórico de três intérpretes). A maior parte desse aumento de definição identitária e de número de componentes se deve à aliança entre JG e Tropicália.

A emersão da Tropicália como intermediário da rede confere a seus atores uma posição privil egiada de influência. Caetano Veloso setorna o mais central dos compositores da rede, partindo do 65ㅇ lugar atingido anteriormente,

Figura 4 - Rede de intérpretes e compositores de 1966 a 1967.

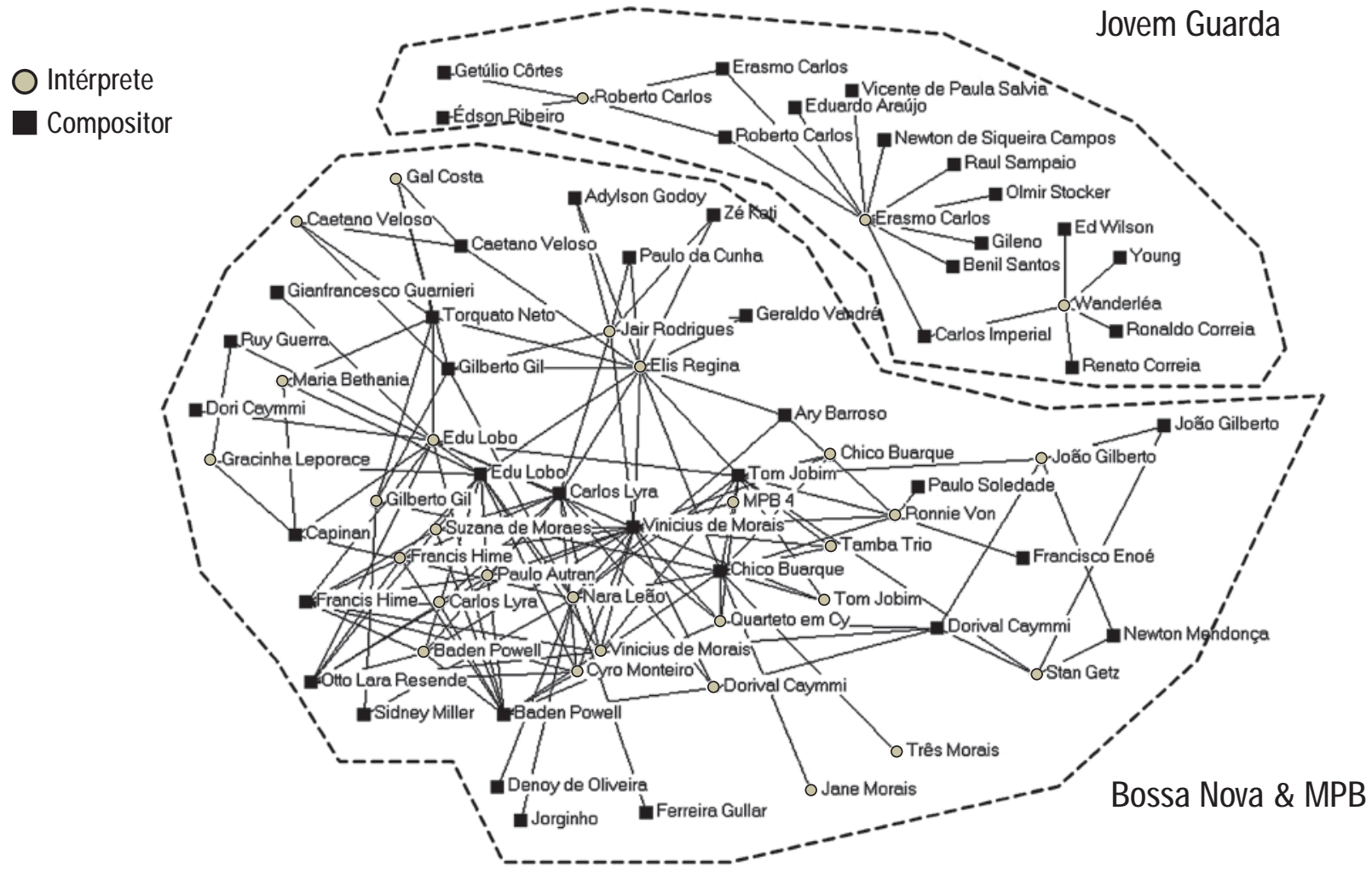


enquanto Gilberto Gil ocupa a 5a posição. Esse deslocamento, contudo, não significa o desaparecimento de players anteriormente bem colocados. A tores tradicionais da BN/M PB e da JG ainda têm importância. Tom Jobim, Vinicius de Moraes, Capinan e Edu Lobo ocupam, respectivamente as 2a 3a $^{\circ}$, 4a e 6a posições, enquanto Erasmo Carlos e Roberto Carlos ficam em 70 e 8ㅇ lugares.

\section{DISCUSSÃO E CONCLUSÃO}

Iniciamos 0 artigo partindo de uma perspectiva racional sobre estratégia: atores racionais se posicionam ao longo da identidade do mercado de maneira a maximizar sua utilidade. Para se estabelecer, é preciso desenvolver uma identidade que se enquadre na identidade geral do mercado. Em outras pal avras, a competição entre atores também se dá em outro nível: uma competição entre categorias (nesse caso, estilos musicais).

No decorrer deste estudo procuramos demonstrar que a identidade, especialmente a "identidade inserida" (embedded identity) não é fixa no tempo: à medida que os intérpretes evoluem em suas carreiras, buscam uma diversificação de repertório, o que causa modificações em seus relacionamentos, tanto com intérpretes pares quanto com os compositores, os quais são a fonte de suas canções. Tal diversificação fornece ao intérprete uma identidade única que será a chave para o avanço de sua carreira.

Ainda assim, a mudança de identidade cria um paradoxo: como será possível mudar uma identidade sem criar perturbação de percepção por parte da indústria e do público? Os artistas almejam singularidade, mas, ao mesmo tempo, não podem romper totalmente com suas comunidades. Se o fizerem, serão marginalizados pela indústria.

Uma solução é a mudança gradual de identidade ( 0 que confirma uma das abordagens sugeridas por Podolny, 1993). Isso se deu com Elis Regina, que estava fortemente ligada à comunidade BN e começou lentamente a introduzir novos compositores (inclusive Gilberto Gil) em seu repertório. Outra solução pode ser observada no

Figura 5 - Rede de intérpretes e compositores de 1968 a 1969.

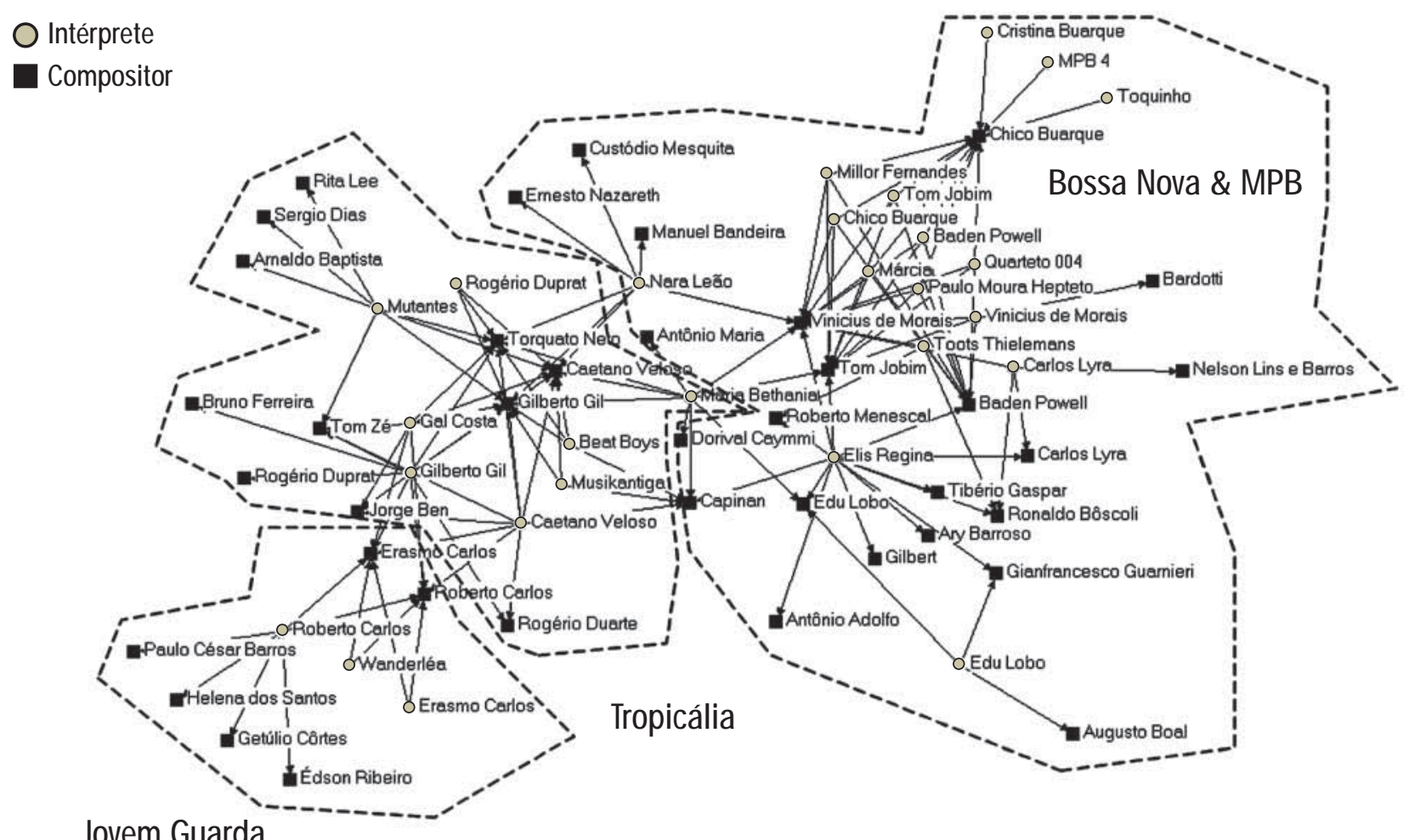


caminho que escolheu Caetano Veloso. Sua mudança de repertório foi abrupta a partir do momento em que adotou canções da JG e ocupou um buraco estrutural que os atores da BN/M PB e da JG haviam deixado para trás (seguindo a segunda abordagem sugerida por Podolny, Caetano Veloso perturbou a ordem simbólica ao introduzir uma identidade que não seguia a dimensão cognitiva existente).

Esses dois caminhos, os traçados por Elis Regina e por Caetano Veloso, sugerem duas maneiras de a inovação ocorrer em redes artísticas. A primeira, evolutiva e sempre legítima, introduz pequenas variações que surtem mudança da identidade percebida a longo prazo. A segunda, revolucionária e no limiar da legitimidade, explora um buraco estrutural e cria um estilo híbrido que não podia ser admitido anteriormente.

Voltemos ao problema original. As empresas e os campos organizacionais circunvizinhos usam de rótulos para aju dar a organizar o fluxo de informações e objetos. 0 colapso da formação de sentido descrito por Weick (1993) ocorrequando o fluxo de experiência não se enquadra nos esquemas cognitivos estabelecidos. No caso aqui descrito, os atores poderiam buscar a mudança por meio de uma adaptação gradual de suas identidades, sem levar a um colapso da formação de sentido existente. Podolny (1993) demonstra que, sendo os atores racionais, não irão contra a identidade estabel ecida do mercado, ainda que ocupem posições desfavoráveis. Ataques propositados ao sistema categórico existente poderiam levar todo o mercado a uma crise de incerteza.

Mas, como sugere o caso da Tropicália, ameaças à ordem simbólica existente podem ocorrer se já tiver sido aceita uma posição subjacente e emergente. Então voltamo-nos para o conceito de 'ação robusta'. Dado que os atores de um campo estão racional mente conectados, não são capazes de conciliar as identidades inseridas concretas no seu conjunto compartilhado de identidades categóricas. Como demonstra Martin (2002), a necessidade de que haja um sistema simbólico fortemente encaixado só ocorre no nível social, não no individual. Com isso, atores estratégicos podem manipular sua identidade inserida de maneira a atingir uma posição que lhes permita, num momento favorável, gerar nova identidade categórica. Há com certeza maior tensão nesse último esforço, uma vez que a criação de uma nova identidade categórica implica mudanças das relações gerais entre as categorias existentes (Bourdieu, 1990).

Ainda assim, a emergência de uma nova categoria respaldada por redes simbólicas preexistentes não leva a um rompimento com o sistema simbólico. Isso se deve a um rearranjo de categorias com base em elos já legitimados. Em nosso exemplo, a emergência da Tropicália enquanto categoria autônoma foi sustentada pela prévia legitimação da interpretação, por Caetano, de canções de Roberto Carlos. Assim, ao contrário da dicotomia que Podolny sugere en tre o consentimento com a ordem simbólica existente e seu rompimento, os atores emergentes podem trilhar um caminho intermediário.

\section{OPORTUNIDADES FUTURAS}

Os insights observados nesta pesquisa encontram-se limitados pela amostra parcial de intérpretes e títul os que foi coletada. Pesquisas futuras podem beneficiar-se de análises ampliadas tanto de intérpretes quanto de LPs.

Ademais, uma vez que a rede se aproxime da população, técnicas mais avançadas de rede social podem ser aplicadas, da modelagem em bloco à análise de papéis estruturais. Com base na rede de compositores, é possível entender como as medidas de buraco estrutural dos atores evoluem frente à evolução de estilos.

Finalmente, a expansão da amostra para que abranja períodos mais recentes poderia fornecer melhor insight sobre as identidades inseridas. Permanecem el as estáveis em face das identidades formais atribuídas pelos críticos musicais?

\section{NOTAS}

1. Há uma vasta bibliografia sobre capital social (ver revisão da literatura em Kadushin, 2004), a tal ponto que podemos estar longe de um consenso no campo. Limitamos nossa discussão ao debate que Burt (2001) propõe entre coesão e equivalência estrutural.

2. Mantivemos o rótulo "Baianos" junto a Tropicália para integrar a este último grupo Maria Bethânia, irmã de Caetano Veloso. Ela resistiu a unirse ao grupo "Tropicalista" como meio de evitar ser classificada como pertencente a algum grupo.

3. Sempre que surge um compositor, recebe um elo consigo mesmo e com seus compositores pares.

4. A medida do 'grau de centralidade' de Freeman é simplesmente 0 número de el os com outros. A versão normalizada dessa medida é dada pela divisão do grau simples pelo máximo grau possível, normalmente $\mathrm{N}-1$, resultando numa medida entre 0 e 1 . Ver Wasserman e Faust (1994), p. 178. 


\section{CHARLES KIRSCHBAUM •FLÁVIO CARVALHO DE VASCONCELOS}

\section{REFERÊNCIAS}

AMORIM, S. G. D.; BARTHELEMY, J. P.; RIBEIRO, C. C. Clustering and clique partitioning: simulated annealing and tabu search approaches. Journal of Classification, v. 9, p. 17-41, 1992.

BERGER, P.; LUCKMAN N, T. The Social Construction of Reality: A Treatise in the Sociology of Knowledge. Garden City, NY: Doubleday, 1966.

BO RGATTI, S. P.; EVERETT, M. G.; FREEMAN, L. C. U cinet for W indows: Software for Social Network Analysis. Cambridge, MA: Analytic Technologies, 2002.

BOURDIEU, P. The forms of capital. In: RICHARDSON, J. G. (Ed.). Handbook of Theory and Research for the Sociology of Education. Westport: Greenwood Press, 1986. p. 241-58.

BOURDIEU, P. Coisas ditas. São Paulo: Brasiliense. 1990. p. 234.

BOURDIEU, P. As regras da arte. São Paulo: Companhia das Letras. 2002

BURT, R. S. Structural Holes. Cambridge, MA: Harvard University Press, 1992.

BURT, R. S. Structural holes versus network closure as social capital. In: LIN , N.; COOK, K.; et al (Eds.). Social Capital: Theory and Research. N ew York: Aldine De Gruyter, 2001.

CALADO, C. Tropicália: a história de uma revolução musical. São Paulo: Editora 34, 1997.

CASTRO, R. Samba-canção, uísque e Copacabana. In: DUARTE, P. S.; CAMBRAIA NAVES, S. (Ed.). D o samba-canção à Tropicália. Rio de Janeiro: Relume Dumará, 2003.

COLEMAN, J. Foundations of Social Theory. Cambridge, MA: Harvard Univ. Press, 1990.

DANTO, A. The art world. The Journal of Philosophy, v. 61, n. 19, p. $571-$ 584,1964

DIMAGGIO, P. J. Classification in art. American Sociological Review, v. 52, n. 4, p. 440-455, ago. 1987.

DIMAGGIO, P. Nadel's paradox revisited: relational and cultural aspects of organizational structures. In: NOHRIA, N.; ECCLES, R. (Eds.). N etworks and Organizations: structure, form, and action. Boston: Harvard Business School Press, 1993.

DOUGLAS, M. How Institutions Think. Syracuse, NY: Syracuse University Press, 1986.
DOWNS, A. U ma teoria econômica da democracia. São Paulo: Edusp, 1999.

DURKHEIM, E. The Elementary Forms of the Religious Life. New York: The Free Press, 1915.

GRANOVETTER, M. S. The strength of weak ties. American Journal of Sociology, v. 78, n. 6, p. 1360-1380, maio 1973

HOGG, M. A.; TERRY, D. J.; WHITE, K. M. A tale of two theories: a critical comparison of identity theory with social identity theory. Social Psychology Quarterly, v. 58, n. 4, p. 255-269, 1995

HOMEM DE MELLO, J. E. Música popular brasileira. São Paulo: Edusp, 1976.

KADUSHIN, C. Too much investment in social capital? Social N etworks, v. 26, n. 1, p. $75-90,2004$

KRACKHARDT, D. The ties that torture: Simmelian tie analysis in organizations. Research in the Sociology of Organizations, v. 16, p. 183-210, 1999.

LAZZARINI, S. G.; JOAQUIM, T. A. Z. A formação de constelações: o caso da indústria global de transporte aéreo. RAE-revista de administração de empresas, v. 44, n. 2, p. 11-25, abr./jun. 2004.

LENA, J. C. Meaning and membership: samples in rap music, 1979-1995. Poetics, v. 32, p. 297-310. 2004

LIMA E SILVA, D. D.; MEDEIROS SOARES, M. et al. The complex network of the Brazilian popular music. Physica A, v. 332, p. 559565,2004

MARTIN, J. L. Power, authority, and the constraint of belief systems American Journal of Sociology, v. 107, n. 4, p. 861-904, 2002

MEDAGLIA, J. Balanço da Bossa N ova. In: CAMPOS, A. D. (Ed.). Balanço da Bossa e outras bossas. São Paulo: Editora Perspectiva, 2003.

PADGETT, J. F.; ANSELL, C. K. Robust action and the rise of the Medici. American Journal of Sociology, v. 98, n. 6, p. 1259-1319, 1993.

PETERSON, R. A. Creating Country Music: Fabricating Authenticity. Chicago: The University of Chicago Press, 1997. p. 306.

PODOLNY, J. M. A status-based model of market competition. The American Journal of Sociology, v. 98, n. 4, p. 829-872, 1993.

PÓLOS, L.; HANNAN, M. T.; CARROLL, G. R. Foundations of a theory of social forms. Ind. Corp. Change, v. 11, p. 85-115, 2002.

POWELL, W. W.; SMITH-DOERR, L. Networks and economic life. In: SMELSER, N. J.; SWEDBERG, R. (Eds.). The Handbook of Economic Sociology. Princeton, NJ: Princeton University Press, 1995. 
RAO, H.; MONIN, P.; DURAND, R. Institutional change in Toque Ville: Nouvelle Cuisine as an identity movement in French gastronomy. American Journal of Sociology, v. 108, n. 4, p. 795-843, jan. 2003.

SCOTT, W. R. Institutions and Organizations. Thousand Oaks, CA: Sage, 2001. p. 255.

SIM MEL, G. The Sociology of Georg Simmel. N ew York: Free Press, 1950.

SIMMEL, G. Fashion. The American Journal of Sociology, v. 62, n. 6, p. 541-558, maio 1957.

TIN HORÃO, J. R. M úsica popular: um tema em debate. São Paulo: Editora 34, 1997.

VELOSO, C. Verdade tropical. São Paulo: Companhia das Letras, 1997. p. 524.

WASSERMAN, S.; FAUST, K. Social Network Analysis: Methods and Applications. Cambridge, UK: Cambridge University Press, 1994.

WEICK, K. The Social Psychology of Organizing. Reading, MA: AddisonWesley Publishing Company, 1969.
WEICK, K. The collapse of sensemaking in organizations: the M ann Gulch disaster. Administrative Science Quarterly, v. 38, n. 4, p. 628-652, 1993.

WEICK, K.; SUTCLIFFE, K.; OBSTFELD, D. Organizing and the process of sensemaking. Organization Science, v. 16, n. 4, p. 409-421, 2005.

WHITE, H. C. Identity and Control. Princeton, NJ: Princeton University Press, 1992.

WHITE, H. C. Careers and Creativity: Social Forces in the Arts. Boulder: Westview Press, 1993.

WHITE, H. C. Markets from Networks: Socioeconomic Models of Production. Princeton, NJ: Princeton University Press, 2002a.

WHITE, H. C. Strategies and Identities by Mobilization Context. Working Paper Series, p. 1-18. Center on Organizational Innovation, Columbia University, NY, 2002b.

ZUCKERMAN, E. W.; KIM, T.-Y. et al. Robust identities or nonentities? Typecasting in the feature-film labor market. American Journal of Sociology, v. 108, n. 5, p. 1018-1074, 2003.

\section{Artigo recebido em 10.08.2004. A provado em 30.05.2006.}

\section{Charles Kirschbaum}

Doutor em Administração pela FGV- EAESP. Professor e Pesquisador do Mestrado em Administração do Centro Universitário da FEl. Pesquisador de Pós-doutorado do Centro de Estudos da M etrópole-Cebrap.

Interesses de pesquisa nas áreas de sociologia da arte, indústria musical, redes sociais, neo-institucionalismo e campos organizacionais.

E-mail: kircharles@fei.edu.br

Endereço: Rua Tamandaré, 688. São Paulo - SP, 01525-000.

\section{Flávio C arvalho de Vasconcelos}

Professor do Departamento de Administração Geral e Recursos Humanos da FGV-EAESP. Interesses de pesquisa nas áreas de estratégia empresarial, teoria organizacional, gestão de pessoas e aprendizagem organizacional.

E-mail: fvasconcelos@fgvsp.br

Endereço: Avenida 9 de Julho, 2029, $9^{\circ}$ andar, São Paulo - SP, 01313-902. 